\title{
Sifat Keperibadian Guru Pendidikan Islam (GPI) Terhadap Rakan Setugas Dan Pihak Atasan Di Sekolah: Satu Kajian Kes
}

\author{
Nazirah Hamdan ${ }^{\text {a }}$ Kamarul Azmi Jasmi \\ ${ }^{a}$ Fakulti Tamadun Islam, Universiti Teknologi Malaysia, 81310 Skudai, Johor \\ *Corresponding author: nazirahhamdan@gmail.com
}

\section{Article history}

Received: 2015-10-20

Received in revised form: 2015-12-08

Accepted: 2016-01-03

\begin{abstract}
This article discussed the Personality Traits of Islamic Education teacher (GPI) towards fellow colleagues and school top management. This study involved several secondary schools in the State of Johor. Interviews, observations, and analysis of documents were used as a data collector instruments. All data were then arranged by using N'Vivo software version 7.0 in order to produce themes, sub-themes and schedule matrix associated with the GPI personality traits towards fellow colleagues and top management. Results of the study indicated twenty one (21) traits that can be established as a pattern and they are committed; compliance; positive thinking; well mannered; respectful; easy going; concerned; have elements of humor; responsible; a role model; sensitive; understanding; tolerance; friendly; diligent; cooperative; approachable; as a point of reference; and unprejudiced. While the other nine (9) traits cannot be established a pattern. Therefore, this study has produced a commendable Personality Traits of Islamic Education teacher (GPI) with Fellow Colleagues and School Top Management Model.
\end{abstract}

Keywords: Personality Traits, Islamic Education teacher, Model of Islamic Education Teacher personality against fellow colleagues and top management.

\begin{abstract}
Abstrak
Artikel ini membincangkan tentang sifat keperibadian guru Pendidikan Islam (GPI) terhadap rakan setugas dan pihak atasan di sekolah. Kajian ini melibatkan beberapa buah sekolah menengah di negeri Johor. Instrumen yang digunakan adalah berbentuk temubual, pemerhatian, dan analisis dokumen. Pentadbiran hasil data kemudian disusun dengan menggunakan perisian N'Vivo versi 7.0 untuk menghasilkan tema, sub-tema dan jadual matriks berkaitan dengan sifat keperibadian GPI kepada rakan setugas dan pihak atasan di sekolah. Hasil dapatan kajian menunjukkan sebanyak 21 sifat yang membentuk pola, iaitu komited; patuh; berfikiran positif; baik; menghormati; mudah didekati; mengambil berat; unsur humor; bertanggungjawab; sebagai role-model; peka; memahami; toleransi; peramah; rajin; kerjasama dan membantu; pendekatan secara hikmah; peramah; menjadi tempat rujukan; mesra; dan tidak mudah menjatuhkan hukuman. Manakala 9 sifat lagi tidak berbentuk pola. Justeru, kajian ini menghasilkan Model Sahsiah Unggul Guru Pendidikan Islam Terhadap Rakan Sejawat dan Pihak Atasan.
\end{abstract}

Kata Kunci: Sifat Keperibadian, guru Pendidikan Islam, Model Sahsiah Unggul GPI Terhadap Rakan Sejawat dan Pihak Atasan 


\subsection{PENGENALAN}

Ajaran agama Islam yang telah disampaikan melalui perutusan baginda Rasulullah SAW sejak 1400 tahun yang lalu telah mengajar serta mendidik manusia dalam setiap aspek kehidupan. Pada zaman awal penyebaran Islam, Rasulullah SAW telah menerima pelbagai kecaman, kritikan, serta cemuhan daripada masyarakat Arab Jahiliah. Hanya segelintir sahaja daripada kalangan mereka yang menerima ajaran yang dibawa oleh Baginda. Namun, melalui keindahan akhlak yang dimiliki oleh Baginda SAW ia telah menjadi sebagai salah satu tarikan utama masyarakat ketika itu untuk menerima ajaran Islam. Hal ini sejajar dengan firman Allah SWT dalam Surah Al-Ahzab (33:21) yang bermaksud; "Sesungguhnya telah ada pada diri Rasulullah SAW itu suri teladan yang baik bagimu (iaitu) bagi orang-orang yang mengharap (rahmat) Allah dan (kedatangan) hari kiamat dan dia banyak menyebut Allah". Terdapat juga petikan hadis yang menyatakan "akhlak Nabi adalah AlQuran" (HR Muslim). Justeru, jelaslah kepada kita bahawa setiap guru khususnya Guru Pendidikan Islam (GPI) haruslah bersifat sebagaimana sifat yang dimiliki oleh Rasulullah SAW kerana GPI memainkan peranan serta menggalas tanggungjawab yang penting dalam menyampaikan ajaran agama Islam bukan hanya di sekolah, malahan kepada masyarakat umum amnya.

Setiap warga pendidik atau lebih dikenali sebagai guru pada hakikatnya menggalas satu amanah yang besar di bahu mereka. Tugas guru pada hari ini menjadi salah satu profesion yang amat mencabar seiring dengan kemajuan zaman teknologi. Menurut Kamarul Azmi et al. (2009) guru agama perlu mengutamakan kecemerlangan dalam menjalankan tugas dan tanggungjawab mereka. Hal ini demikian kerana Guru Pendidikan Islam (GPI) bukan sahaja berhadapan dengan pelajar di sekolah, malahan juga perlu berdepan dengan kerenah ibubapa dan penjaga pelajar, dan masyarakat. Oleh yang demikian, adalah perlu bagi setiap guru khususnya guru yang mengajar subjek Pendidikan Islam, atau lebih dikenali sebagai 'ustaz' dan 'ustazah' menjaga tingkah laku dan berkeperibadian mulia.

\subsection{OBJEKTIF DAN PERSOALAN KAJIAN}

Kajian ini adalah bertujuan mengkaji sifat keperibadian Guru Pendidikan Islam (GPI) terhadap rakan sejawatan dan pihak atasan di sekolah menengah. Persoalan kajian ialah "bagaimana sifat keperibadian yang sering menjadi amalan dalam diri Guru Pendidikan Islam di sekolah terhadap rakan sejawatan dan pihak atasan mereka?

\subsection{METODOLOGI KAJIAN}

Cohen dan Manion (1996) menyatakan bahawa metodologi adalah pendekatan yang digunakan dalam penyelidikan pendidikan bagi pengumpulan data. Kajian yang dijalankan ini adalah berbentuk kualitatif atau lebih menjurus kepada kajian kes atau lebih tepat lagi sebagai kajian pelbagai kes (multiple case) sebagai salah satu bentuk keesahan data kajian (Merriam, 2002). Metode utama yang digunakan oleh pengkaji dalam kajian ini ialah temubual bagi mendapatkan maklumat yang khusus dalam mengumpulkan maklumat.

Kajian temubual merupakan sesuatu yang unik kerana ia melibatkan proses pengumpulan data melalui lisan antara dua pihak secara langsung (Sang, 2010). Kaedah ini digunakan untuk mengkaji beberapa individu yang terpilih atau sesuai digunakan dalam kajian yang memerlukan pengumpulan data daripada persampelan yang besar (Othman, 2014). Justeru, seramai 7 orang GPI terpilih sebagai responden utama dalam kajian ini, selain turut melibatkan 14 orang rakan GPI, 14 orang pelajar, dan 7 orang pihak atasan GPI yang terpilih sebagai informan. Kaedah pemerhatian terhadap sample kajian dan analisis dokumen dilaksanakan sebagai sokongan kepada data temubual. Kriteria pemilihan GPI ini ialah:, (1) pengalaman mengajar 1- 5 tahun, (2) pengalaman mengajar 5-10 tahun, (3) pengalaman mengajar 10 tahun ke atas, (4) guru cemerlang Pendidikan Islam, dan (5) peratusan sekolah mencapai 95\% ke atas dalam subjek Pendidikan Islam dalam Peperiksaan Menengah Rendah (PMR). Hasil temubual ini kemudiannya akan ditranskripsi menjadi data naratif dan seterusnya analisis dibuat melalui perisian N' Vivo 7.0 bagi membina tema dan sub-sub tema kajian. 


\subsection{DAPATAN KAJIAN}

Setelah dianalisis secara mendalam, pengkaji telah mengenalpasti tema kajian serta mendapati bahawa guru Pendidikan Islam di S1-S7 bersifat dengan beberapa sifat yang terpuji. Dapatan data adalah seperti yang tertera dalam Jadual 1 berikut:

Jadual 1: Pola Sifat Keperibadian diri Guru Pendidikan Islam terhadap rakan sejawatan dan pihak atasan di sekolah

\begin{tabular}{|c|c|}
\hline Tema & Kod \\
\hline Komited & $\begin{array}{l}\text { Menerima setiap tugas yang diberikan } \\
\text { Memastikan kehadiran pelajar setiap waktu solat } \\
\text { Menjaga hal ehwal kebajikan Pendidikan Islam di sekolah } \\
\text { Sangat aktif } \\
\text { Imam solat sejurus masuk waktu solat }\end{array}$ \\
\hline Bekerjasama dan membantu & $\begin{array}{l}\text { Saling tolong-menolong } \\
\text { Senang berurusan } \\
\text { Jenis tidak berkira } \\
\text { Kerjasama yang sangat baik } \\
\text { Rajin membantu }\end{array}$ \\
\hline Bertanggungjawab & $\begin{array}{l}\text { Guru Pembimbing } \\
\text { Mementingkan pelajar } \\
\text { Menyelesaikan masalah disiplin sekolah } \\
\text { Hasil kerja yang baik } \\
\text { Memantau aktiviti kelab, persatuan, dan panitia Pendidikan Islam } \\
\text { Mengajar dengan semaksimum }\end{array}$ \\
\hline Baik & $\begin{array}{l}\text { Orang yang baik } \\
\text { Hubungan baik dengan guru } \\
\text { Hubungan rapat } \\
\text { Program dapat berjalan dengan baik }\end{array}$ \\
\hline Tempat Rujukan & $\begin{array}{l}\text { Selalu dijadikan tempat rujukan } \\
\text { Beri pendapat jika ditanya } \\
\text { Bersedia membantu }\end{array}$ \\
\hline $\begin{array}{l}\text { Mesra, Peramah \& Mudah di } \\
\text { Dekati }\end{array}$ & $\begin{array}{l}\text { Mesra alam } \\
\text { Boleh bergaul } \\
\text { Friendly } \\
\text { Hubungan seperti adik-beradik } \\
\text { Boleh bergaul dengan semua orang } \\
\text { Sangat mesra } \\
\text { Suka bercerita } \\
\text { Tidak sombong } \\
\text { Matang }\end{array}$ \\
\hline Patuh & $\begin{array}{l}\text { Ikut kehendak pentadbir } \\
\text { Ikut keperluan sekolah } \\
\text { Kolaborasi dengan pentadbir yang sangat baik } \\
\text { Tidak menolak kerja }\end{array}$ \\
\hline Humor & $\begin{array}{l}\text { Sense of humor } \\
\text { Suka bergurau } \\
\text { Pandai berjenaka } \\
\text { Lawak }\end{array}$ \\
\hline Role-Model & $\begin{array}{l}\text { Beri contoh yang baik daripada guru biasa } \\
\text { Penampilan pakaian yang sempurna } \\
\text { Pelajar nak jadi macam ustaz/ustazah }\end{array}$ \\
\hline Toleransi dan memahami & $\begin{array}{l}\text { Memahami keadaan } \\
\text { Bertolak-ansur } \\
\text { Tidak menolak kerja } \\
\text { Senang berurusan } \\
\text { Saling faham-memahami } \\
\text { Meredakan suasana yang tegang }\end{array}$ \\
\hline Mengambil Berat & $\begin{array}{l}\text { Mengambil berat tentang guru lain } \\
\text { Sangat berdedikasi }\end{array}$ \\
\hline
\end{tabular}




\begin{tabular}{|l|l|}
\hline Berfikiran Positif & $\begin{array}{l}\text { Tidak berprasangaka buruk } \\
\text { Reda } \\
\text { Menerima teguran dengan terbuka } \\
\text { Boleh berbincang dengan baik }\end{array}$ \\
\hline Menghormati & $\begin{array}{l}\text { Hormat guru yang lebih berusia } \\
\text { Pertuturan yang lemah-lembut dan tersusun }\end{array}$ \\
\hline Pendekatan Secara Hikmah & $\begin{array}{l}\text { Bijak menggunakan kaedah yang sesuai untuk menegur } \\
\text { Berdakwah } \\
\text { Berbudi-bahasa }\end{array}$ \\
\hline Peka & $\begin{array}{l}\text { Perkembangan semasa } \\
\text { Mengingatkan rakan lain }\end{array}$ \\
\hline Rajin & $\begin{array}{l}\text { Pengemas } \\
\text { Bilik yang bersih }\end{array}$ \\
\hline $\begin{array}{l}\text { Tidak Mudah Menjatuhkan } \\
\text { Hukuman }\end{array}$ & $\begin{array}{l}\text { Pendekatan secara hikmah } \\
\text { Berbincang terlebih dahulu }\end{array}$ \\
\hline
\end{tabular}

Berdasarkan Jadual 1, hasil kajian menunjukkan beberapa sifat keperibadian GPI terhadap rakan sejawatan dan pihak atasan di sekolah, dan membentuk pola kajian. Sifat-sifat tersebut ialah seperti komited, bekerjasama dan membantu, bertanggungjawab, baik, menjadi tempat rujukan hal agama, mesra dan peramah, patuh, mudah didekati, unsur humor, toleransi, mengambil berat, berfikiran positif, menghormati, pendekatan secara hikmah, peka, memahami, rajin, tidak mudah menjatuhkan hukuman, dan sebagai role-model.

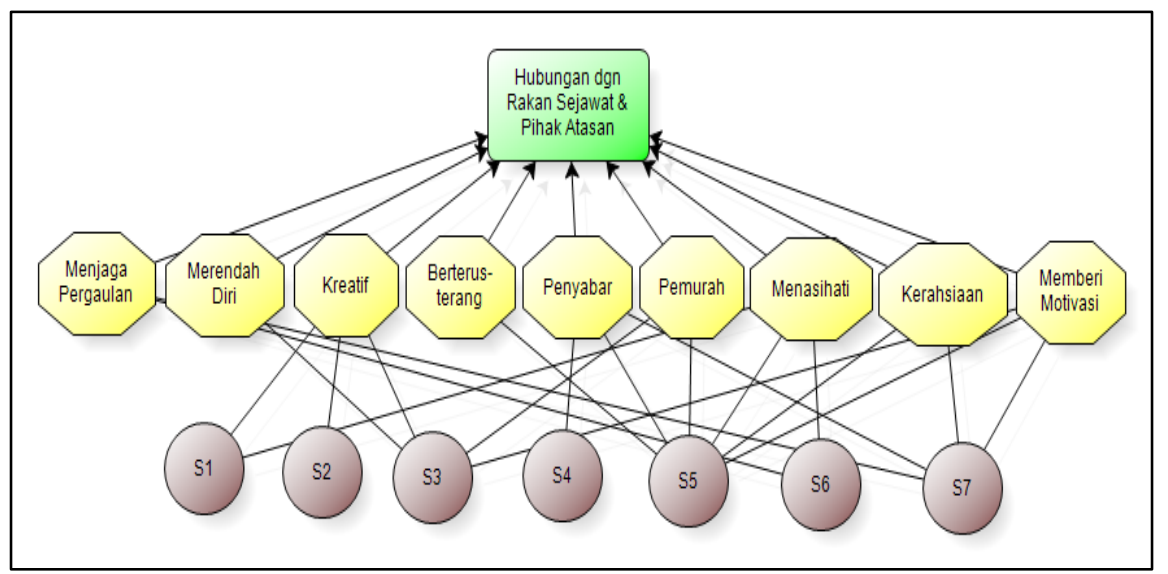

Carta 1: Pengamalan Sifat Keperibadian Diri GPI yang Tidak Membentuk Pola

Carta 1 adalah hasil kajian yang merupakan sifat keperibadian GPI yang tidak membentuk pola kajian. Ia terdiri daripada sembilan sifat, iaitu menjaga pergaulan, merendah diri, kreatif, berterusterang, penyabar, pemurah, menasihati, kerahsiaan, dan memberi motivasi. Berdasarkan carta ini, jika dibandingkan dengan GPI yang lain GPIS5 dilihat memiliki beberapa sifat, iaitu, menasihati, memberi motivasi, pemurah, penyabar, menjaga kerahsiaan, dan berterus-terang. Manakala GPI yang selebihnya adalah bersifat dengan kadar yang sederhana.

\subsection{PERBINCANGAN KAJIAN}

Perbincangan yang berhubung dengan sifat keperibadian Guru Pendidikan Islam (GPI) terhadap rakan sejawatan dan pihak atasan di sekolah terdiri daripada beberapa sifat mahmudah. Data kajian menunjukkan sifat komited yang ditunjukkan oleh GPI di S1-S7 mendominasi sifat-sifat yang lain. Hal ini dapat dilihat melalui sikap GPI yang tidak pernah menolak sebarang kerja yang diamanahkan kepada mereka, menjaga segala hal ehwal yang berkaitan dengan Pendidikan Islam di sekolah, memastikan kehadiran pelajar di surau untuk solat berjemaah dan sekaligus menjadi imam solat. Keadaan ini dibuktikan melalui petikan temubual bersama rakan dan pihak atasan GPI yang menyatakan "Ok, puan Sharimah ni yang saya nampak dia akan bertanya kalau apa yang dia tak tahu nak buat dia akan bertanya, dan apa yang perlu dia buat memang dia akan buat" (PAGPIS5, 2014). Sifat lain yang diterapkan oleh GPI dalam diri mereka ialah sifat memberikan kerjasama dan membantu. Penyelidik menggabungkan juga beberapa sikap yang lain seperti bertanggungjawab, 
patuh, dan rajin kerana dilihat memiliki ciri persamaan yang boleh digabungkan antara satu sama lain. Pernyataan ini dijelaskan melalui kata-kata berikut, "sifat lain macam kerjasama, contoh kalau ada majlis Maulidur Rasul yang lepas ni, bahagian panitia Pendidikan Islam yang handle kan..jadi dia boleh buat.."(R1GPIS1, 2012), “dia bertanggungjawab..”(PAGPIS2, 2012), dan “dia dedikasi..komited pada kerja..dia tak melawan pihak atasan lah..hehee..integriti dia pada kerja tu sangat kuat lah..taat..kalau pengetua minta apa-apa dia tak membantah lah..”. Yahya dan Zainuddin (2003) dalam kajian mereka turut mendapati bahawa sifat tanggungjawab GPI adalah tinggi, iaitu sebanyak 86.8\%. Kenyataan ini disokong oleh Abdul Ghani et al. (2010) dan Ahmad Zamri et al. (2010) yang menyatakan bahawa penerapan sifat komited, bertanggungjawab, patuh, dan rajin ini akan menjadi aspek positif serta dapat mengembangkan potensi kerja sesebuah organisasi.

Seorang guru yang disukai dan disayangi ramai pada kebiasaannya adalah seorang yang baik hatinya. Hal ini dapat dilihat ada dalam diri GPI di S1-S7 yang mana kajian temubual mendapati masyarakat sekolah membenarkan kenyataan tersebut. Hal ini dapat dilihat melalui kata-kata rakan GPI "Kesimpulan dia baiklah... (ketawa) baiklah..baiklah" (R2GPIS3, 2012), "dia memang seorang yang baiklah.."(PAGPIS5, 2014). Selain itu, dengan mengamalkan sifat toleransi serta saling memahami, dan menghormati antara sesama rakan guru dan pihak atasan menjadikan GPI sebagai seorang yang berkeperibadian mulia. Sebagai contoh, petikan temubual bersama GPI ini menyatakan "contohnya ustazah Fatiha ni kan akan berkahwin, dia sorang je lagi guru agama yang belum berkahwin daripada awal ni kita dah bagi dia support lah, bagi keringanan kalau tugasan tu macam yang memerlukan hujung minggu dia tak perlulah datang jangan libatkan dia sebab kita pun tahu dia sibukkan untuk menguruskan majlis" (GPIS5, 2014). Penerapan sifat ini adalah selari dengan kajian yang dibuat oleh Abdul Ghani et al. (2010), yang menyatakan melalui sikap saling hormat menghormati sesama rakan di tempat kerja ia akan membantu diri untuk menerima individu lain dan dapat mengelakkan berlakunya konflik dan salah faham sekiranya berlaku.

Sebagai salah satu usaha bagi memupuk pertalian atau perhubungan yang baik dalam kalangan warga sekolah, hasil kajian mendapati GPI juga seorang yang bersifat mesra, peramah, senang didekati, memiliki sifat humor dalam diri, dan berfikiran terbuka. Aspek ini dinilai daripada temubual bersama rakan, pelajar, dan pihak atasan GPI. Dalam kalangan mereka menyatakan GPI adalah seorang yang sangat mesra, membina hubungan sesama rakan sekerja seperti adik-beradik, tidak sombong, dan boleh bergaul dengan semua orang. Sebagai contoh, petikan kata-kata "Dia punya hubungan dia, lebih daripada hubungan adik beradik. ha..tu boleh nampak.."(R1GPIS2, 2012), "Ustaz macam selalu bergurau senda dengan cikgu-cikgu lainlah terutamanya cikgu lelaki.."(P2S7, 2014) dan "ha, berjenaka satu lagi keistimewaan dia.."(R1GPIS3, 2012). Pengamalan sifat-sifat ini diperlukan oleh GPI kerana ia selari dengan kajian Ling (2015) yang mendapati bahawa dengan memiliki sifat ini akan mewujudkan kepuasan kerja dalam diri seseorang pendidik kerana keterbukaan sikap menerima kritikan jika ada, di samping dapat menyesuaikan diri dalam perubahan.

Seiring dengan tanggungjawab GPI yang mengajar subjek Pendidikan Islam di sekolah, kajian menunjukkan GPI menjadi tempat rujukan dalam hal yang berhubung masalah atau isu keagamaan khususnya dalam kalangan warga sekolah. Hal ini diakui oleh rakan dan pelajar GPI di S1-S7 yang menyatakan mereka akan merujuk kepada ustaz atau ustazah di sekolah jika terdapat kemusykilan agama. Contohnya, "Haa..ada..kadang-kadang akak pun suka juga bertanya tentang puasa, hubungan kita dengan orang bukan Islam, itu antara akak sendiri lah..macam mana aurat kita kalau berhadapan dengan orang bukan Islam, sejauh mana sebenarnya kita perlu berpakaian sesama perempuan lah..lelaki kita tahu..hehe..macam-macam juga la..macam-macam lah.." (PAGPIS1, 2012). Melalui keperibadian mahmudah yang ditonjolkan ini juga secara tidak langsung manjadikan GPI sebagai role-model dalam kalangan warga sekolah. Hal ini ditekankan oleh Ab. Halim dan Mohamad Khairul (2010) supaya GPI menjadi role-model atau qudwah hasanah serta menjadi ejen perubahan bagi membentuk masyarakat melalui sistem pendidikan.

Akhir sekali, GPI di S1-S7 juga dilihat memiliki sifat peka serta mengambil berat tentang hal yang berlaku dalam ruang lingkup sekolah. Sikap ini secara tidak langsung menjadikan GPI mengetahui setiap perkembangan terkini yang berlaku di persekitaran mereka. Hal ini dapat dibuktikan melalui kata-kata berikut, "kena peka dengan perkembangan semasa.." (GPIS1, 2012), "kalau apa-apa hal yang berkaitan pentadbiran, atau sebagainya beliau akan mengingatkan pada yang lain.." (R1GPIS5, 2014). Dapatan ini selari dengan kajian yang dibuat oleh Ahmad Zamri et al. 
(2010), iaitu seorang guru pada hakikatnya mampu memberikan pengaruh yang positif kepada rakan sejawatan yang lain melalui penerapan nilai-nilai yang positif seperti keperihatinan, komitmen, dan keterbukaan antara mereka.

\subsection{IMPLIKASI DAN CADANGAN KAJIAN}

Melalui hasil analisis kajian, penyelidik membina satu model yang dinamakan sebagai Model Sahsiah Unggul Guru Pendidikan Islam Terhadap Rakan Sejawat dan Pihak Atasan. Model ini digambarkan sebagaimana yang terpapar di Rajah 1 .

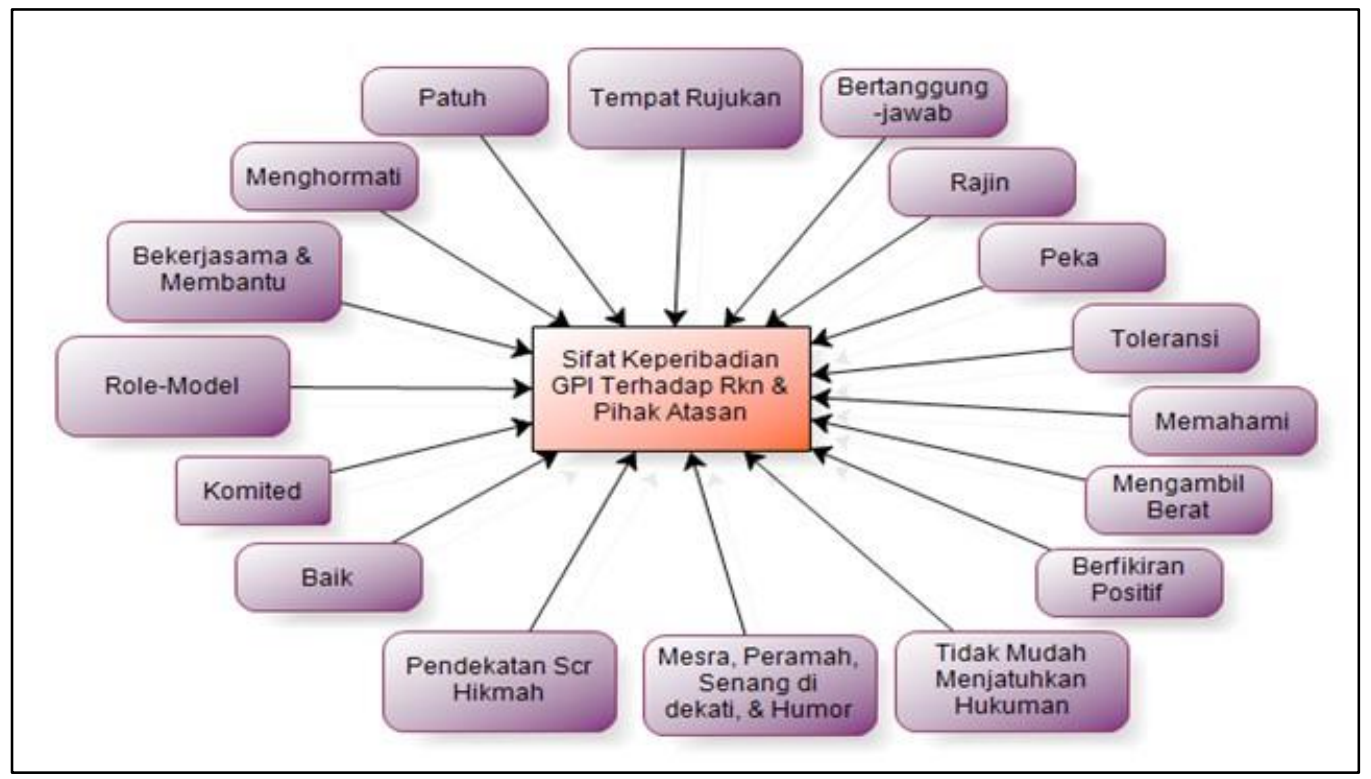

Rajah 1: Model Sifat Keperibadian GPI Terhadap Rakan Sejawat dan Pihak Atasan.

Berdasarkan Rajah 1, kesemua sifat keperibadian yang telah dikenalpasti ini boleh diamal dan diterapkan dalam diri bukan hanya kepada GPI tetapi kepada seluruh warga pendidik amnya. Namun begitu, GPI haruslah bijak dalam mengendalikan emosi dan sikap mereka agar bersesuaian dengan situasi, tempat, dan suasana.

\subsection{KESIMPULAN}

Berdasarkan kajian ini, pengkaji telah membincangkan perkara yang berkaitan objektif, persoalan kajian, metodologi kajian dan hasil analisis kajian tentang sifat keperibadian GPI terhadap rakan sejawatan dan pihak atasan mereka di sekolah. Justeru, hasil kajian yang membentuk pola telah membina satu model, iaitu Model Sifat Keperibadian GPI Terhadap Rakan Sejawat dan Pihak Atasan. Justeru, penyelidik berharap agar model ini dapat menjadi panduan kepada guru khususnya GPI bagi memperbaiki dan memperindahkan lagi sahsiah diri untuk menjadi lebih baik, seiring dengan gelaran ustaz dan ustazah yang disandang oleh mereka, bukan hanya di sekolah malahan dalam kehidupan seharian.

\subsection{RUJUKAN}

Ab. Halim, Tamuri, dan Mohamad Khairul, Azman Ajuhary. (2010). Amalan Pengajaran Guru Pendidikan Islam Berkesan Berteraskan Konsep Mu'allim. Journal of Islamic and Arabic Education, 2(1), 43-56.

Abdul Ghani, Kanesan Abdullah, Al-Amin, Mydin, dan Aziah, Ismail (2010). Pembangunan Kerohanian di Tempat Kerja. Educators Digest (Diges Pendidik), 10(2), 14-20.

Ahmad Zamri, Khairani, Nordin, Ab. Razak, dan Mohammad Zohir, Ahmad@Shaari. (2010). Tugas dan Tanggungjawab Guru Pembimbing dari Perspektif Guru Pelatih. Malaysian Education Dean's Council Journal, 10. 
GPIS1. (2012). Ciri-ciri Kecemerlangan Guru Pendidikan Islam. In Nazirah Hamdan (Ed.), Kajian Lapangan Ph.D (pp. 1-14). Surau S1, SMK Taman Desa Skudai: FTI, UTM.

GPIS5. (2014). Ciri-ciri Kecemerlangan Guru Pendidikan Islam. In Nazirah Hamdan (Ed.), Kajian Lapangan Ph.D (pp. 1-19). Surau Al-Hikmah S5, Sek. Men. (P) Sultan Ibrahim Johor Bahru: FTI, UTM.

Kamarul Azmi, Jasmi, Ab.Halim, Tamuri, dan Mohd Izham, Mohd Hamzah. (2009). Sifat dan Peranan Keperibadian Guru Cemerlang Pendidikan Islam (GCPI) dan Hubungannya dengan Motivasi Pelajar. Jurnal Teknologi, 51(E), 57-71. .

Ling, Ying Leh. (2015). Hubungan Antara Amalan Penilaian Pensyarah dengan Kepuasan Kerja Pensyarah di Politeknik Kuching Sarawak. Malaysian Education Dean's Council Journal, 9.

Merriam, Sharan B. (2002). Qualitative Research In Practice: Example For Discussion And Analysis (pp. 3-17). San Francisco: Jossey-Bass.

Othman, Lebar. (2014). Penyelidikan Kualitatif Pengenalan Kepada Teori dan Metode. Tanjung Malim Perak: Universiti Pendidikan Sultan Idris.

P2S7. (2014). Ciri-ciri Kecemerlangan Guru Pendidikan Islam In Nazirah Hamdan (Ed.), Kajian Lapangan Ph.D (pp. 1-11). Surau S7, Sek. Men. Keb. Dato' Penggawa Barat: FTI, UTM.

PAGPIS1. (2012). Ciri-ciri Kecemerlangan Guru Pendidikan Islam. In Nazirah Hamdan (Ed.), Kajian Lapangan Ph.D (pp. 1-28). Bilik Ketua Bidang S1, SMK Taman Desa Skudai: FTI, UTM.

PAGPIS2. (2012). Ciri-ciri Kecemerlangan Guru Pendidikan Islam. In Nazirah Hamdan (Ed.), Kajian Lapangan Ph.D (pp. 1-51). Bilik Guru Penolong Kanan 1 S1, SMK Taman Universiti: FTI, UTM.

PAGPIS5. (2014). Ciri-ciri Kecemerlangan Guru Pendidikan Islam. In Nazirah Hamdan (Ed.), Kajian Lapangan Ph.D (pp. 1-19). Bilik Guru-guru Kanan S5, Sek. Men. (P) Sultan Ibrahim Johor Bahru: FTI, UTM.

R1GPIS1. (2012). Ciri-ciri Kecemerlangan Guru Pendidikan Islam. In Nazirah Hamdan (Ed.), Kajian Lapangan Ph.D (pp. 1-7). Bilik Guru S1, SMK Taman Desa Skudai: FTI, UTM.

R1GPIS2. (2012). Ciri-ciri Kecemerlangan Guru Pendidikan Islam. In Nazirah Hamdan (Ed.), Kajian Lapangan Ph.D (pp. 1-19). Perpustakaan S2, SMK Taman Universiti: FTI, UTM.

R1GPIS3. (2012). Ciri-ciri Kecemerlangan Guru Pendidikan Islam. In Nazirah Hamdan (Ed.), Kajian Lapangan Ph.D (pp. 1-53). Bilik Guru S3, SMK Tun Fatimah Johor Bahru: FTI, UTM.

R1GPIS5. (2014). Ciri-ciri Kecemerlangan Guru Pendidikan Islam. In Nazirah Hamdan (Ed.), Kajian Lapangan Ph.D (pp. 1-19). Bilik Sumaiyah S5, Sek. Men. (P) Sultan Ibrahim Johor Bahru: FTI, UTM.

R2GPIS3. (2012). Ciri-ciri Kecemerlangan Guru Pendidikan Islam. In Nazirah Hamdan (Ed.), Kajian Lapangan Ph.D (pp. 1-66). Bilik Guru S3, SMK Tun Fatimah Johor Bahru: FTI, UTM.

Sang, Mook Soon. (2010). Penyelidikan dalam Pendidikan Perancangan dan Pelaksanaan Penyelidikan Tindakan. Puchong, Selangor: Penerbitan Multimedia Sdn.Bhd.

Yahya, Buntat, dan Zainuddin, Masrom. (2003). Amalan Etika Profesion Perguruan di Kalangan Guru-guru Sekolah Kebangsaan Kampung Melayu, Kulai Johor. Satu Tinjauan. Jurnal Teknologi, $38(\mathrm{E}), 65-74$. 